\title{
Evaluation of Biosorption Capacity of Methylglycinediacetic Acid Modified Pericarp of Gossypium herbaceum L. for Cadmium (II) Removal from Aqueous Solution
}

\author{
Nikhil Teli ${ }^{1}$, Satish Bhalerao ${ }^{2}$, Deepa R. Verma ${ }^{3}$ \\ Assistant Professor, VIVA College of Arts, Commerce and Science, Department of Environmental Sciences, \\ Virar- 401305, Affiliated to University of Mumbai, Maharashtra, India ${ }^{1}$ \\ Ex-Head and Professor, Department of Botany, Wilson College, \\ Mumbai-400 007, Affiliated to University of Mumbai, Maharashtra, India ${ }^{2}$ \\ Assistant Professor, VIVA College of Arts, Commerce and Science, Department of Botany, Virar- 401305, \\ Affiliated to University of Mumbai, Maharashtra, India ${ }^{3}$
}

\begin{abstract}
Increased usage of heavy metals for industrial activities has resulted in an increased concentration of these metals in waste water. Presence of heavy metals in wastewater is of great interest because of their known toxic effects on the nearby environment. In this study, the removal of cadmium (II) ions from an aqueous solution using Methylglycinediacetic acid (MGDA) modified pericarp of Gossypium herbaceum L. as a green adsorbent, in batch condition was investigated. The equilibrium studies were systematically carried out in a batch process which covered a various process parameter inclusive of $\mathrm{pH}$, contact time, temperature, adsorbent dose, agitation rate and initial ion concentration. The adsorption equilibrium data were adequately characterized by Langmuir, Freundlich, Temkin and DKR isotherm models. Best fitting isotherm models were in the following order, Langmuir $\left(R^{2}=0.9996\right)>$ Freundlich $\left(R^{2}=0.9974\right)>$ Temkin $\left(R^{2}=0.9637\right)>D K R\left(R^{2}=0.899\right)$. The adsorption kinetics was found to follow pseudo-secondorder rate kinetic model. Thermodynamic study confirmed that the biosorption process was endothermic, spontaneous and proceeded with increased randomness. All results showed that the MGDA modified pericarp of Gossypium herbaceum L. is an alternative low-cost green adsorbent for removal of cadmium (II) ions from an aqueous solution.
\end{abstract}

Keywords: Methylglycinediacetic acid, Gossypium herbaceum L., cadmium (II), isotherm\

\section{INTRODUCTION}

Water contaminated with several heavy metals is discharged annually by a number of industries. Heavy metals like lead, cadmium, chromium, zinc and copper contamination in wastewater is primarily come from manmade sources like battery, electronics, paper and pulp industries, metal fabrication and mining activities, smelting, electrolysing, drug manufacturing, paint preparation, alloy manufacturing, galvanizing, printing, dyeing, paper making, ceramics manufacturing and inorganic dyestuff preparation etc. [1]. Untreated and uncontrolled discharge of metal containing wastewater into the environment could be toxic to humans, animals, plants and to urban ecosystems [2].

Removal of heavy metals from the effluent is very significant part of the research carried out in the field of environmental science. Over the last few periods, numerous treatment and management methodologies have been used for the elimination of heavy metals from water and waste water. The conventional methods such as chemical precipitation, ultrafiltration, ion exchange, reverse osmosis, electrodialysis, cementation, coagulation \& flocculation and solvent extraction seems to be ineffective or quite expensive or require long duration for heavy metal ion removal from waste water. Hence, efforts are currently being made to develop novel technologies that are cost effective, eco-friendly and highly efficient to remove the metal ions. In this endeavour, biosorption has emerged as an alternative and sustainable strategy for cleanup water. Biosorption is a physico-chemical process, simply defined as the removal of contaminants from solution by biological materials. It uses inexpensive biomaterials to sequester environmental pollutants from aqueous solutions by a wide range of physicochemical mechanisms including ion exchange, chelation, coordination, complexation, physical adsorption, and surface microprecipitation [3]. The search for innovative green ways for removal of heavy metals has forced attention on the use of new natural materials for removal of metal ions. 


\section{DOI: 10.17148/IARJSET.2021.8909}

The research will emphasis on the removal of Cd(II) from its aqueous solution by Methylglycinediacetic acid modified pericarp (fruit wall) of Gossypium herbaceum L.(GhMGDA) as green adsorbent. The study was conducted with the objective for optimization of various process parameters affecting the biosorption of metals such as solution $\mathrm{pH}$, contact time, temperature, adsorbent dose, agitation rate and initial $\mathrm{Cd}(\mathrm{II})$ ) metal ion concentration. Adsorption isotherms, kinetics and thermodynamic studies were employed to understand the probable biosorption mechanism.

\section{EXPERIMENTAL METHODS OR METHODOLOGY}

\subsection{Preparation of Chemicals and Reagents}

All the chemicals and reagents utilized for experimental work were of analytical reagent (AR) grade. The desired $\mathrm{pH}$ of the metal ion solution was adjusted with the help of $0.1 \mathrm{~N} \mathrm{HCl}$ and $0.1 \mathrm{~N} \mathrm{NaOH}$ solutions. $1000 \mathrm{ppm}$ of Cd(II) was prepared by dissolving $2.032 \mathrm{~g}$ of cadmium chloride $(\mathrm{CdCl} 2)$ in Millipore water and the volume was made to the mark in a $1000 \mathrm{~cm} 3$ volumetric flask using Millipore water. Further desired working solutions of cadmium (II) were prepared using appropriate subsequent dilutions of the stock solution.

\subsection{Preparation of green adsorbent}

Pericarp (fruit wall) of Gossypium herbaceum L. (Family: Malvaceae) was collected from Ahmednagar District. Initially, it was washed with tap water and then after with distilled water to remove the dust and other impurities. The washed green adsorbent was initially dried at room temperature for a week and then in an oven at $50{ }^{\circ} \mathrm{C}$ for 24 hrs and grounded in a mechanical grinder to form powder. The green adsorbent powder was sieved through $250 \mu \mathrm{m}$ size sieve. Methylglycinediacetic acid modification of green adsorbent was carried out according to a similar method described by Zhu et. al., (2008) [4]. For the modification of green adsorbent by Methylglycinediacetic acid, 50 gm Gossypium herbaceum pericarp powder was added in $200 \mathrm{~mL}$ of $1 \%$ MGDA and the mixture was heated at $50{ }^{\circ} \mathrm{C}$ for $2 \mathrm{hrs}$. The sample was filtered and the liquid fraction was discarded and treated powder dried in an oven at $60{ }^{\circ} \mathrm{C}$ for $24 \mathrm{hrs}$. After that, the temperature of an oven was raised up to $100{ }^{\circ} \mathrm{C}$ for $120 \mathrm{~min}$. The dried MGDA modified green adsorbent was subsequently rinsed with double distilled water to eliminate excess of MGDA. Finally, the modified green adsorbent was dried in hot air oven at $60{ }^{\circ} \mathrm{C}$ for $48 \mathrm{hrs}$. The dried Methylglycinediacetic acid modified pericarp of Gossypium herbaceum (GhMGDA) green adsorbent powder was stored in air tight container to protect it from moisture.

\subsection{Batch biosorption studies}

The batch adsorption method was employed at temperature $\left(30^{\circ} \mathrm{C}\right)$ to study the biosorption of Cd(II) by GhMGDA. Different experimental conditions such as solution $\mathrm{pH}$, contact time, temperature, adsorbent dose, agitation rate and initial $\mathrm{Cd}(\mathrm{II})$ ion concentration were optimized. The concentration of $\mathrm{Cd}(\mathrm{II})$ in the solutions before and after equilibrium was determined by measuring absorbance using Atomic Absorption Spectrophotometer (Agilent; Model: AA 240 FS). The following equation was used to compute the percent adsorption of Cd(II) by the GhMGDA adsorbent,

$\%$ Adsorption $=\frac{\left(C_{i}-C_{e}\right)}{C_{i}} \times \mathbf{1 0 0}$

Where, $C_{i}$ and $C_{e}$ are the initial concentration and equilibrium concentration of the Cd(II) in $\mathrm{mg} / \mathrm{L}$.

The equilibrium adsorptive quantity $\left(q_{e}\right)$ was estimated by the following equation,

$q_{e}=\frac{\left(C_{i}-C_{e}\right)}{w} \times V$

Where, $q_{e}$ (mg metal per g dry biosorbent) is the amount of $\mathrm{Cd}(\mathrm{II})$ biosorbed, $V$ (in liter) is the solution volume and $w$ (in gram) is the amount of dry green adsorbent used.

Adsorption isotherm studies were systematically carried out by considering Langmuir, Freundlich, DubininRadushkevich (DKR) and Temkin adsorption isotherm models. Determination of adsorption kinetics was studied with the help of Pseudo-first-order, Pseudo-second-order, Elovich and Weber and Morris intraparticle diffusion kinetics model. Thermodynamic parameters such as Gibbs free energy $\left(\Delta \mathrm{G}^{\circ}\right)$, change in enthalpy $\left(\Delta \mathrm{H}^{\circ}\right)$ and change in entropy $\left(\Delta \mathrm{S}^{\circ}\right)$ have also been estimated. 
DOI: 10.17148/IARJSET.2021.8909

3. RESULTS AND DISCUSSION

\subsection{Batch biosorption study}

\subsubsection{Effect of $\mathbf{p H}$}

The solution $\mathrm{pH}$ can have a significant effect on the adsorption of $\mathrm{Cd}(\mathrm{II})$. The effect of $\mathrm{pH}$ onto $\mathrm{Cd}(\mathrm{II}) \mathrm{metal}$ ions by GhMGDA as adsorbents were analysed over the pH range from 2 to 10. The Fig. 1 indicates that the adsorption was found to increase up to maximum; when $\mathrm{pH}$ was increased from 1 to 6 . Further increase in $\mathrm{pH}$ leads to slight decrease in the \% adsorption of Cd(II) by GhMGDA. Hence, optimum $\mathrm{pH}$ was found to be $\mathrm{pH} 6$ with $90.987 \% \mathrm{Cd}$ (II) removal by GhMGDA. The lesser adsorption at lower $\mathrm{pH}$ was due to lesser surface sites are available for sorption. This is due to the fact that proton $\mathrm{H}+$ ) vies with cadmium ions in lower $\mathrm{pH}$, the sorbent surface takes up more $\mathrm{H}+$, consequently, reducing cadmium ions bind on the sorbent surface. In higher $\mathrm{pH}$, the sorbent surface takes more negative changes, thus attracting greater cadmium ions. However, with a further increase in $\mathrm{pH}$, the formation of anionic hydroxide complexes decreases the concentration of free cadmium ion, and thereby, the biosorption capacity of cadmium ion decreased [5].

\subsubsection{Effect of adsorbent dose}

The green adsorbent dosage is an important parameter because this determines the capacity of a green adsorbent for a given initial concentration. The biosorption efficiency for $\mathrm{Cd}(\mathrm{II})$ ions as a function of green adsorbent dosage was investigated at $30{ }^{\circ} \mathrm{C}$ temperature by varying the amount of sorbents from 0.1 to $0.6 \mathrm{~g} / 50 \mathrm{ml}, 120 \mathrm{rpm}$ for $90 \mathrm{~min}$ using initial $\mathrm{Cd}(\mathrm{II})$ concentration of $100 \mathrm{mg} / \mathrm{L}$ and at $\mathrm{pH}$ value of 6.0. The percentage of adsorbed cadmium by GhMGDA increases with increasing dosage of green adsorbent. It can be observed from Fig. 2 that the adsorption of Cd(II) increased from $47.667 \%$ to $90.901 \%$ by varying GhMGDA green adsorbent dosage from $0.1 \mathrm{~g}$ to $0.5 \mathrm{~g}$. Increase in adsorption by increase in green adsorbent dose is because of increase of ion exchange site ability, surface areas and the number of available adsorption sites [6].

\subsubsection{Effect of initial metal ion concentration}

The extent of removal of heavy metals from aqueous solution depends on the initial metal ion concentration. Adsorption capacity of GhMGDA for Cd(II) adsorption at various initial concentrations of Cd(II) ranging from $20 \mathrm{mg} / \mathrm{L}$ to $100 \mathrm{mg} / \mathrm{L}$ is presented in Fig. 3. The experiment was conducted by maintaining the contact time at 90 minutes, $\mathrm{pH} 6,0.5 \mathrm{~g}$ of adsorbent dose $(0.5 \mathrm{~g} / 50 \mathrm{ml})$, agitation rate $120 \mathrm{rpm}$ and temperature at $30{ }^{\circ} \mathrm{C}$. As can be seen in the Fig. 3 , percentage removal of $\mathrm{Cd}(\mathrm{II})$ ions to some extent decreased with the increase in initial $\mathrm{Cd}(\mathrm{II})$ ions concentration by GhMGDA adsorbent, which shows a significant relationship between the removal efficiency and initial metal concentration. In case of low metal ion concentrations, a greater number of vacant sites are available for adsorption which results rise in the concentration slope and rate of cadmium ions spread to adsorbent. In the case of high concentration of metal, the obtainable sites of green adsorbents are decreases and therefore the removal percentage of Cd(II) ions decreases [7].

\subsubsection{Effect of contact time}

The contact time is one of the important parameters affecting the biosorption process. It is very useful to design a successful biosorption procedure. The effect of contact time on biosorption of Cd(II) ions by GhMGDA are shown in Fig. 4. There is a significant increase in the biosorption efficiency with time by GhMGDA. The maximum removal of Cd(II) was found to be $90.995 \%$ by GhMGDA after 90 minutes of contact time. This is a relatively fast adsorption process. The fast adsorption in the initial stage of adsorption was attributed to the large number of active sites available $[8]$.

\subsubsection{Effect of temperature}

Fig. 5 illustrates $\mathrm{Cd}(\mathrm{II})$ sorption on GhMGDA at different temperatures. It can be inferred from the graph that sorption of Cd(II) was significantly increased from $10{ }^{\circ} \mathrm{C}$ to $50{ }^{\circ} \mathrm{C}$ by GhMGDA. This observation could be attributed to the fact that more chemical sites were present as temperature rises. This also suggests that the adsorption mechanism of Cd(II) ion on green adsorbents could be chemical sorption in addition to physical sorption in which sorption increases with an increase in temperature [9].

\subsubsection{Effect of agitation rate}

Experiment was carried out by taking Cd(II) ion concentration $100 \mathrm{mg} / \mathrm{L}$, adsorbent dose $0.5 \mathrm{~g} / 50 \mathrm{ml}$, pH 6, contact time of 90 minutes and temperature at $30^{\circ} \mathrm{C}$ with varying agitation speed $(0-200 \mathrm{rpm})$. The effect of agitation speed on the 


\section{DOI: 10.17148/IARJSET.2021.8909}

adsorption of $\mathrm{Cd}(\mathrm{II})$ ions is shown in Fig. 6. As agitation speed increased up to $120 \mathrm{rpm}$, adsorption capacity of GhMGDA for removal of $\mathrm{Cd}(\mathrm{II})$ also increased from $32.954 \%$ to $90.492 \%$. Further increase in agitation speed resulted in significant decrease in removal efficiency of $\mathrm{Cd}(\mathrm{II})$ by GhMGDA.

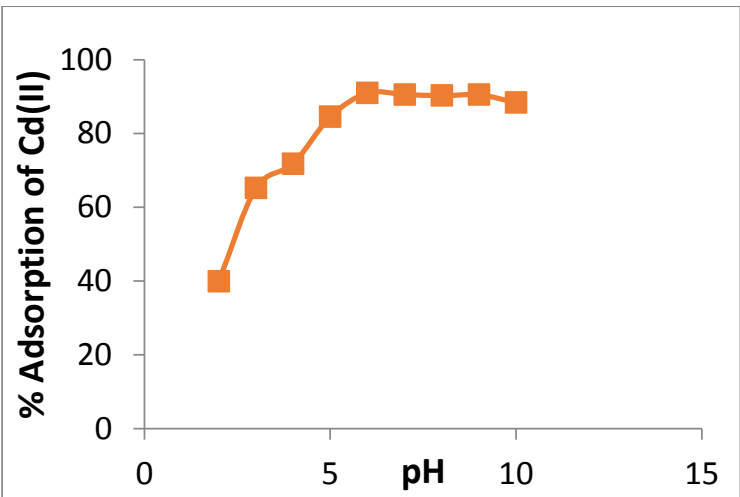

Fig. 1: Effect of $\mathrm{pH}$ on $\mathrm{Cd}(\mathrm{II})$ biosorption by GhMGDA (Adsorbent dose : $0.5 \mathrm{~g} / 50 \mathrm{ml}, \mathrm{Cd}(\mathrm{II})$ concentration: $100 \mathrm{mg} / \mathrm{L}$, Contact time: 90 minutes, Temperature: $30{ }^{\circ} \mathrm{C}$, Agitation rate: $120 \mathrm{rpm}$ )

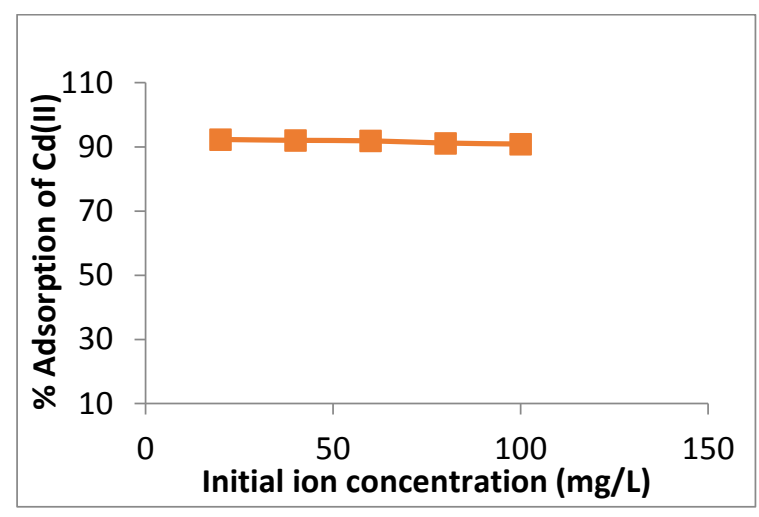

Fig. 3: Effect of initial $\mathrm{Cd}(\mathrm{II})$ ion concentration on biosorption by GhMGDA (pH: 6, Adsorbent dose: $0.5 \mathrm{~g} / 50 \mathrm{ml}$, Contact time: 90 minutes, Temperature: $30{ }^{\circ} \mathrm{C}$, Agitation rate: $120 \mathrm{rpm}$ )

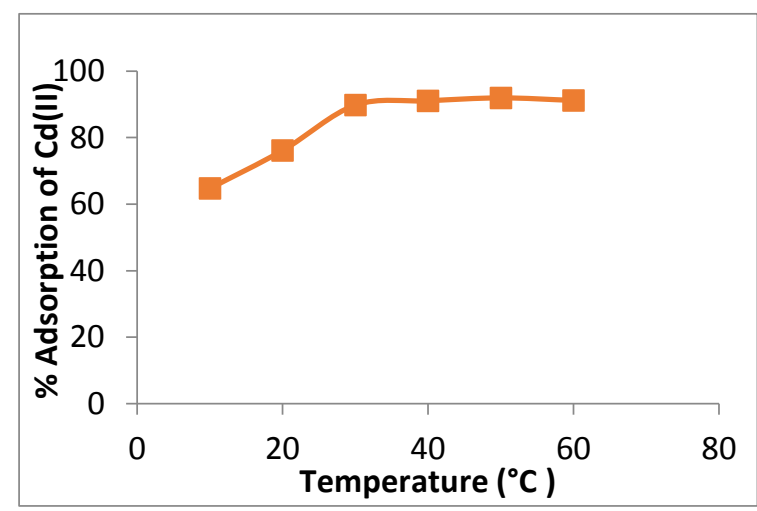

Fig. 5: Effect of temperature on Cd(II) biosorption by GhMGDA (pH: 6, Adsorbent dose: $0.5 \mathrm{~g} / 50 \mathrm{ml}$, Cd(II) concentration: $100 \mathrm{mg} / \mathrm{L}$, Contact time: 90 minutes, Agitation rate: 120 rpm)

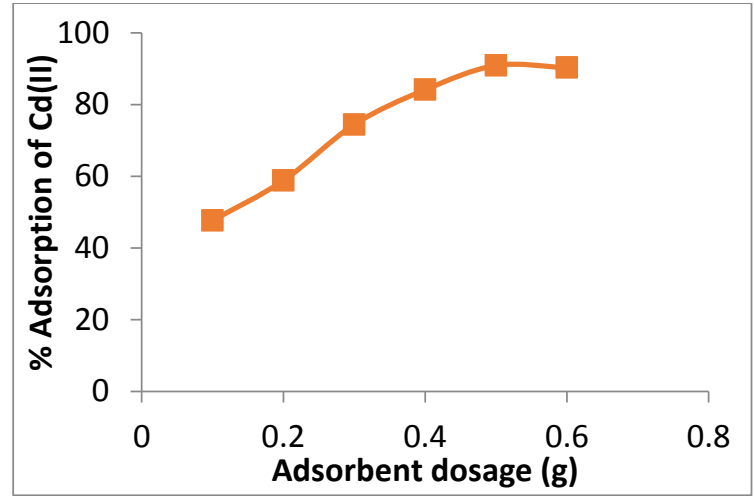

Fig. 2: Effect of adsorbent dose on $\mathrm{Cd}(\mathrm{II})$ biosorption by GhMGDA (pH: 6, Cd(II) concentration: 100 mg/L, Contact time: 90 minutes, Temperature: 30 ${ }^{\circ} \mathrm{C}$, Agitation rate: $120 \mathrm{rpm}$ )

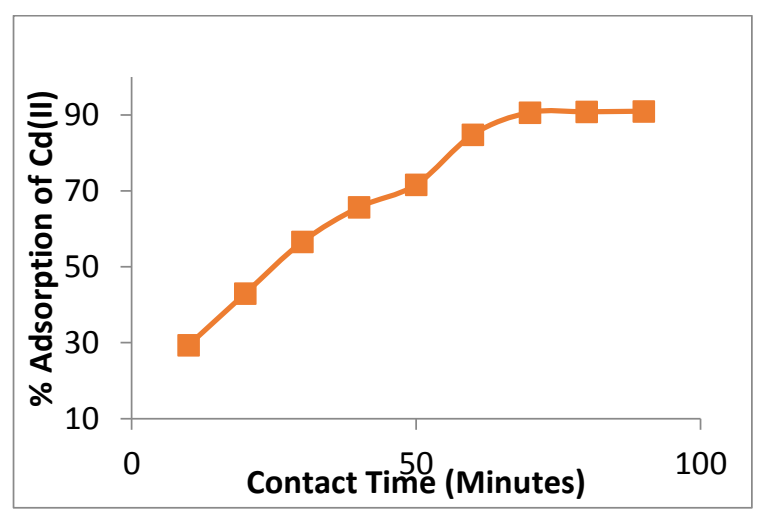

Fig. 4: Effect of contact time on $\mathrm{Cd}(\mathrm{II})$ biosorption by GhMGDA (pH: 6, Adsorbent dose: $0.5 \mathrm{~g} / 50 \mathrm{ml}$, Cd(II) concentration: $100 \mathrm{mg} / \mathrm{L}$, Temperature: 30 ${ }^{\circ} \mathrm{C}$, Agitation rate: $120 \mathrm{rpm}$ )

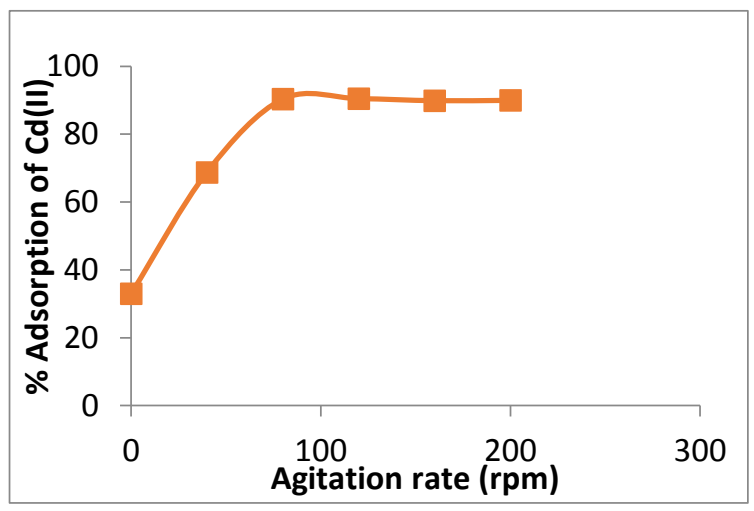

Fig. 6: Effect of agitation rate on $\mathrm{Cd}(\mathrm{II})$ biosorption by GhMGDA (pH: 6, Adsorbent dose: $0.5 \mathrm{~g} / 50 \mathrm{ml}$, Cd(II) concentration: $100 \mathrm{mg} / \mathrm{L}$, Contact time: 90 minutes, Temperature: $30{ }^{\circ} \mathrm{C}$ 


\section{International Advanced Research Journal in Science, Engineering and Technology}

Vol. 8, Issue 9, September 2021

\subsection{Adsorption isotherm study}

The results obtained from the biosorption of Cd(II) ions on GhMGDA was investigated using adsorption isotherm models: Langmuir, Freundlich, Dubinin-Kaganer-Radushkevich (DKR) and Temkin to describe the equilibrium between the metal ions sorbed on to the green adsorbent as shown in Table 1.

\subsubsection{Langmuir isotherm}

The Langmuir equation is valid for monolayer sorption onto a surface of finite number of identical sites [10], which is given by;

$q=\frac{q_{m} b C_{e}}{1+b C_{e}}$

Where $q_{m}$ is the maximum biosorption capacity of biosorbent $\left(\mathrm{mg} \mathrm{g}^{-1}\right), b$ is the Langmuir biosorption constant $\left(\mathrm{L} \mathrm{mg}^{-1}\right)$ related to the affinity between the biosorbent and biosorbate.

The linearized Langmuir isotherm allows the calculation of biosorption capacities and Langmuir constants and is represented as follows:

$\frac{1}{q e}=\frac{1}{q_{m} b C_{e}}+\frac{1}{q_{m}}$

The linear plots of $1 / q_{e}$ vs $1 / c_{e}$ is shown in Fig. 7 (a). Constants $b$ and $q_{m}$ are computed from the slope $\left(1 / q_{m} \cdot b\right)$ and intercept $\left(1 / q_{m}\right)$ of the line and the values are listed in Table 1.

\subsubsection{Freundlich adsorption isotherm}

The Freundlich isotherm, which assumes that the adsorption occurs on heterogeneous surface of an adsorbent with interaction between the adsorbate molecules. Freundlich equation is represented by;

$q=K C_{e}^{1 / n}$

Where $K$ and $n$ are empirical constants which incorporating all parameters affecting the process of biosorption such as, biosorption capacity and biosorption intensity respectively [11]. Linearized Freundlich adsorption isotherm was used to determine the sorption data and is represented as:

$\log q e=\log K+\frac{1}{n} \log C_{e}$

Equilibrium data for the biosorption process is plotted as $\log q_{e}$ vs $\log C_{e}$, as shown in Fig. 7 (b). Constants $n$ and $K$ are calculated from the slope $(1 / n)$ and intercept $(\log K)$ of the line, respectively and the values are listed in Table 1 .

\subsubsection{Dubinin-Kaganer-Radushkevich (DKR) adsorption isotherm}

The linearized Dubinin-Kaganer-Radushkevich (DKR) adsorption isotherm equation is represented as;

$\ln q_{e}=\ln q_{m}-\beta \varepsilon^{2}$

Where $q_{m}$ is the maximum biosorption capacity, $\beta$ is the activity coefficient related to mean biosorption energy and $\varepsilon$ is the polanyi potential [12], which is calculated from the following relation;

$\varepsilon=R \ln \left(1+\frac{1}{C_{e}}\right)$

Equilibrium data for the adsorption is plotted as $\ln q_{e}$ vs $\varepsilon^{2}$, as shown in Fig. 7 (c). Constants $\beta$ and $q_{m}$ are calculated from the slope $(\beta)$ and intercept $\left(\ln q_{m}\right)$ of the line, respectively and the values of adsorption energy $E$ was obtained by the following relationship, 


\section{International Advanced Research Journal in Science, Engineering and Technology}

Vol. 8, Issue 9, September 2021

DOI: 10.17148/IARJSET.2021.8909

$E=\frac{1}{\sqrt{-2 \beta}}$

The $\mathrm{E}$ value was found to be $0.7454 \mathrm{KJ} \mathrm{mol}^{-1}$. The mean free energy gives an idea about biosorption mechanism; whether it is physical or chemical biosorption. If the value of $\mathrm{E}$ is less than $8 \mathrm{KJ} \mathrm{mol}^{-1}$, then the biosorption process can be explained by physisorption mechanism, if $\mathrm{E}$ is between 8 and $16 \mathrm{KJ} \mathrm{mol}^{-1}$, the process is dominated by ion exchange mechanism, and if $\mathrm{E}$ is $>16 \mathrm{KJ} \mathrm{mol}^{-1}$, the biosorption process is dominated by chemisorption [13]. In the present work, E value $\left(0.7454 \mathrm{KJ} \mathrm{mol}^{-1}\right)$ which is less than $8 \mathrm{KJ} \mathrm{mol}^{-1}$, the biosorption of $\mathrm{Cd}(\mathrm{II})$ ions onto GhMGDA is of physical in nature.

\subsubsection{Temkin adsorption isotherm}

The linearized Temkin adsorption isotherm is given by the equation;

$q_{e}=\frac{R T}{b_{T}} \ln A_{T}+\frac{R T}{b_{T}} \ln C_{e}$

Where $b_{T}$ is the Temkin constant related to heat of biosorption ( $\left.\mathrm{J} / \mathrm{mol}\right)$ and $A_{T}$ is the Temkin isotherm constant (L/g) [14]. Equilibrium data for the adsorption is plotted as $q_{e} \mathrm{vs} \ln C_{e}$, as shown in Fig. 7 (d). The two constants $b_{T}$ and $A_{T}$ are calculated from the slope $\left(R T / b_{T}\right)$ and intercept $\left(R T / b_{T} \cdot \ln A_{T}\right)$ of the line and the values are listed in Table 1.
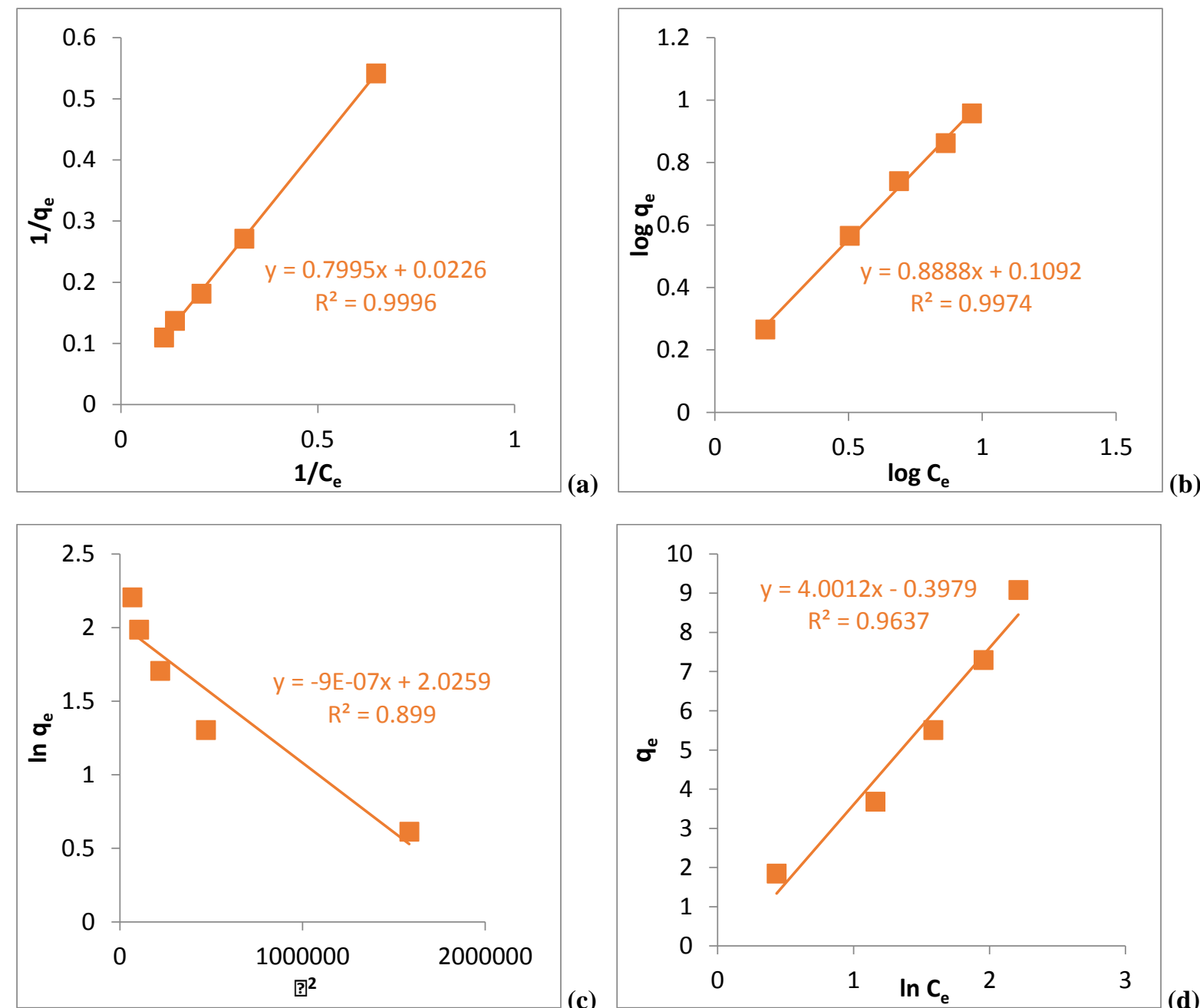

(a)

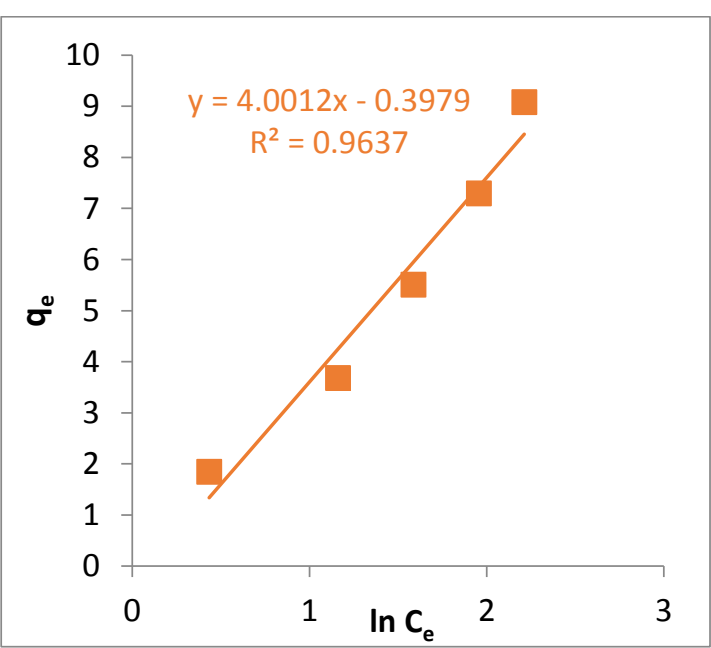

(b)

(c)

Fig. 7: Adsorption isotherms (a) Langmuir, (b) Freundlich (c) DKR and (d) Temkin for Cd(II) biosorption by GhMGDA (pH: 6.0, Adsorbent dose: $0.5 \mathrm{gm} / 50 \mathrm{ml}$, Contact time: 90 minutes, Temperature: $30{ }^{\circ} \mathrm{C}$, Agitation rate: $120 \mathrm{rpm})$ 
International Advanced Research Journal in Science, Engineering and Technology

Vol. 8, Issue 9, September 2021

DOI: 10.17148/IARJSET.2021.8909

Table 1: Adsorption isotherm constants for Cd(II) biosorption by GhMGDA

\begin{tabular}{|l|l|l|l|l|l|l|l|l|l|l|l|l|l|}
\hline \multicolumn{4}{|l|}{ Langmuir parameters } & \multicolumn{3}{l|}{ Freundlich parameters } & \multicolumn{3}{l|}{ DKR parameters } & \multicolumn{3}{l|}{ Temkin parameters } \\
\hline $\boldsymbol{q}_{\boldsymbol{m}}$ & $\boldsymbol{b}$ & $\boldsymbol{R}^{2}$ & $\boldsymbol{K}$ & $\mathbf{1 / n}$ & $\boldsymbol{R}^{2}$ & $\boldsymbol{\beta}$ & $\boldsymbol{q}_{\boldsymbol{m}}$ & $\boldsymbol{E}$ & $\boldsymbol{R}^{2}$ & $\boldsymbol{A}_{\boldsymbol{T}}$ & $\boldsymbol{b}_{\boldsymbol{T}}$ & $\boldsymbol{R}^{\mathbf{2}}$ \\
\hline 44.25 & 0.028 & 0.9996 & 1.2859 & 1.1251 & 0.9974 & $-9 \times 10^{-7}$ & 7.58 & 0.745 & 0.899 & $\begin{array}{l}0.905 \\
4\end{array}$ & 0.6296 & 0.9637 \\
\hline
\end{tabular}

\subsection{Adsorption kinetics studies}

Kinetic parameters of an adsorption process are crucial for the estimation of adsorption parameters, which in turn control the entire process of sorption, which are thus vital for designing sorption systems. The sorption kinetics of a system are controlled by different steps, including transfer of solute to the sorbent particle surface, transfer from the sorbent surface to the intra-particle active sites and retention on these active sites via sorption, complexation or intra-particle precipitation phenomena [15]. To determine the controlling mechanism of the biosorption process, experimental data were scrutinized for pseudo-first-order equation [16], pseudo-second-order equation [17], Elovich equation [18] and Weber \& Morris intra-particle diffusion equation [19] which is presented below;

$\ln \left(q_{e}-q_{t}\right)=\ln q_{e}-k_{1} t$

$\frac{t}{q_{t}}=\frac{1}{k_{2} q_{e}^{2}}+\frac{t}{q_{e}}$

$q_{t}=\frac{1}{\beta} \ln (\alpha \beta)+\frac{1}{\beta} \ln t$

$q_{t}=k_{i} t^{0.5}+c$

Where $q_{e}\left(\mathrm{mg} \mathrm{g}^{-1}\right)$ is the solid phase concentration at equilibrium, $q_{t}\left(\mathrm{mg} \mathrm{g}^{-1}\right)$ is the average solid phase concentration at time $t(\mathrm{~min}), k_{1}\left(\mathrm{~min}^{-1}\right)$ and $k_{2}\left(\mathrm{~g} \mathrm{mg}^{-1} \mathrm{~min}^{-1}\right)$ are the pseudo-first-order and pseudo-second-order rate constants, respectively. The $\alpha\left(\mathrm{mg} \mathrm{g}^{-1} \mathrm{~min}^{-1}\right)$ and $\beta\left(\mathrm{g} \mathrm{mg}^{-1}\right)$ are Elovich coefficients indicating initial biosorption rate and desorption constants, respectively. $k_{i}\left(\mathrm{mg} \mathrm{g}^{-1} \mathrm{~min}^{-1 / 2}\right)$ is the intra-particle diffusion rate constant, $c$ is intercept.

If the biosorption process follows the pseudo-first-order model, a plot of $\ln \left(q_{e^{-}} q_{t}\right)$ against time $t$ should be a straight line. Similarly, $t / q_{t}$ should change lineally with time $t$ if the biosorption process obeys the pseudo-second order model. If the biosorption process obeys Elovich model, a plot of $q_{t}$ against $\ln t$ should be a straight line. Also, a plot of $q_{t}$ against $t$ 0.5 changes lineally the biosorption process obeys the Weber and Morris intra-particle diffusion model [20].

Biosorption of $\mathrm{Cd}(\mathrm{II})$ onto GhMGDA was monitored at different specific time interval. The Cd(II) uptake was calculated from the data obtained.

The pseudo-first-order model was plotted for $\ln \left(q_{e}-q_{t}\right)$ against $\mathrm{t}$ as shown in the Fig.8 (a). The values of $k_{l}$ and $q_{e}$ were estimated from the slope $\left(k_{l}\right)$ and intercept $\left(\ln q_{e}\right)$ of the plot and shown in Table 2. Pseudo-first-order model exhibited the correlation value $\left(R^{2}=0.8312\right)$ being lower than the correlation coefficient for the pseudo-second-order model. Kinetic biosorption for pseudo-first-order model occurs chemically and involves valency forces through ion sharing or exchange of electron between the biosorbent and the ions adsorbed onto it [21].

The pseudo-second-order model was plotted for $t / q_{t}$ against $\mathrm{t}$ as shown in the Fig.8 (b). The values of $q_{e}$ and $k_{2}$ are calculated from the slope $\left(1 / q_{e}\right)$ and intercept $\left(1 / k_{2} q_{e}^{2}\right)$ of the plot and values are shown in Table 2. Pseudo-second-order kinetic model revealed the strongest correlation $\left(R^{2}=0.9809\right)$. This finding indicates that Cd(II) biosorption follows in a monolayer fashion and which relies on the assumption that chemisorption or chemical adsorption is the rate-limiting step. $\mathrm{Cd}(\mathrm{II})$ reacts chemically with the specific binding sites on the surface of biosorbent [21].

The Elovich model was plotted for $q_{t}$ against $\ln t$ as shown in the Fig. 8 (c). The values of $\beta$ and $\alpha$ are calculated from the slope $(1 / \beta)$ and the intercept $(\ln (\alpha \beta) / \beta)$ of the plot and values are shown in Table 2 . The Elovich model has been used with the assumption that the actual adsorption surface is energetically heterogeneous [22]. The Elovich model showed a correlation coefficient $\left(R^{2}=0.9742\right)$. 
DOI: 10.17148/IARJSET.2021.8909

The Weber \& Morris intra-particle diffusion model was plotted for $q_{t}$ against $t^{0.5}$ as shown in the Fig. 8 (d). The value of $k_{i}$ and $c$ are calculated from the slope $\left(k_{i}\right)$ and intercept $(c)$ of the plot and values are shown in Table 2. The Weber and Morris intra-particle diffusion model showed a $\left(R^{2}=0.9343\right)$ being lower than the correlation coefficient for the pseudosecond-order model. The intercept of the plot does not pass through the origin, this is indicative of some degree of boundary layer control and intra-particle pore diffusion is not only rate-limiting step [19, 24].
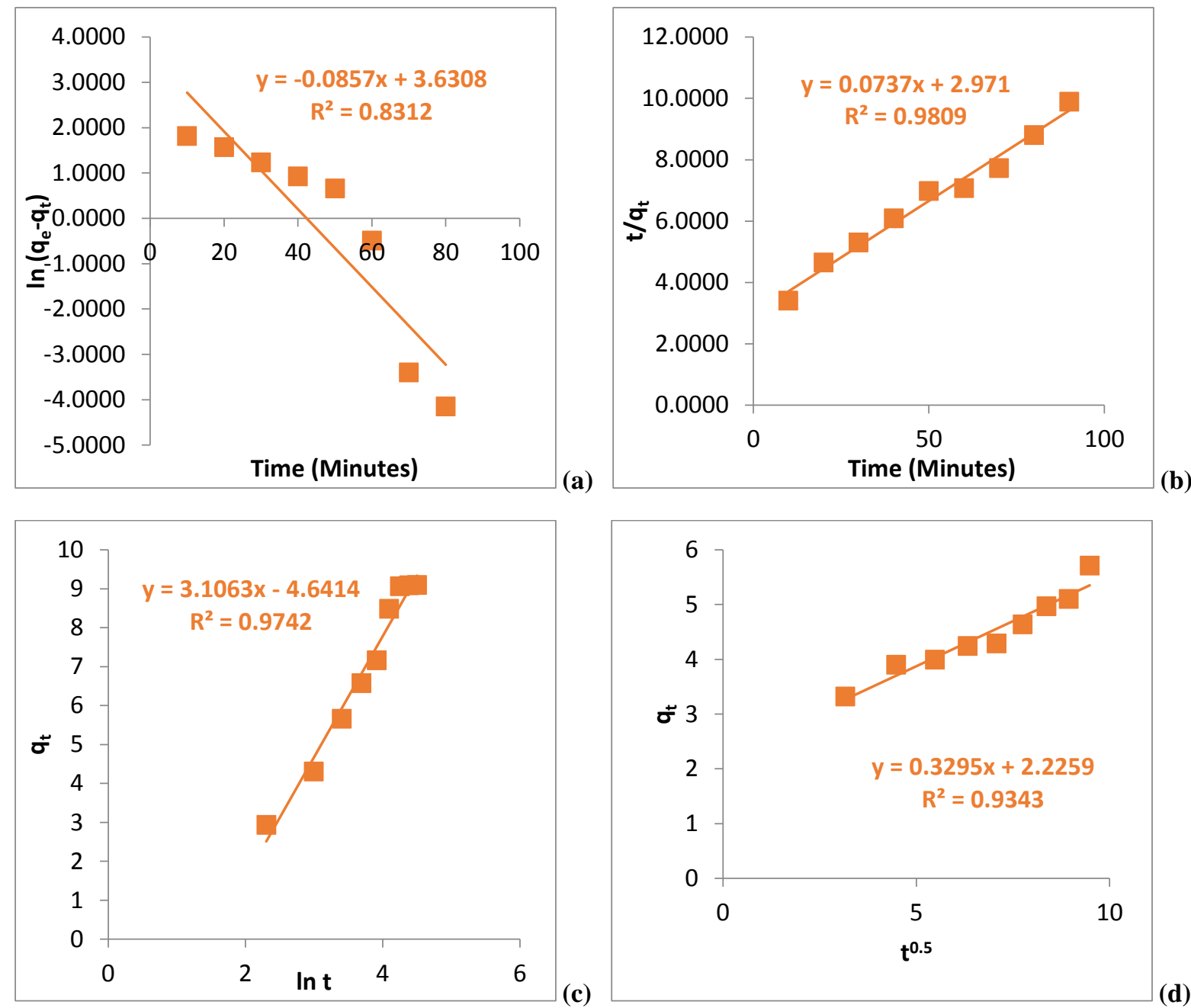

(a)

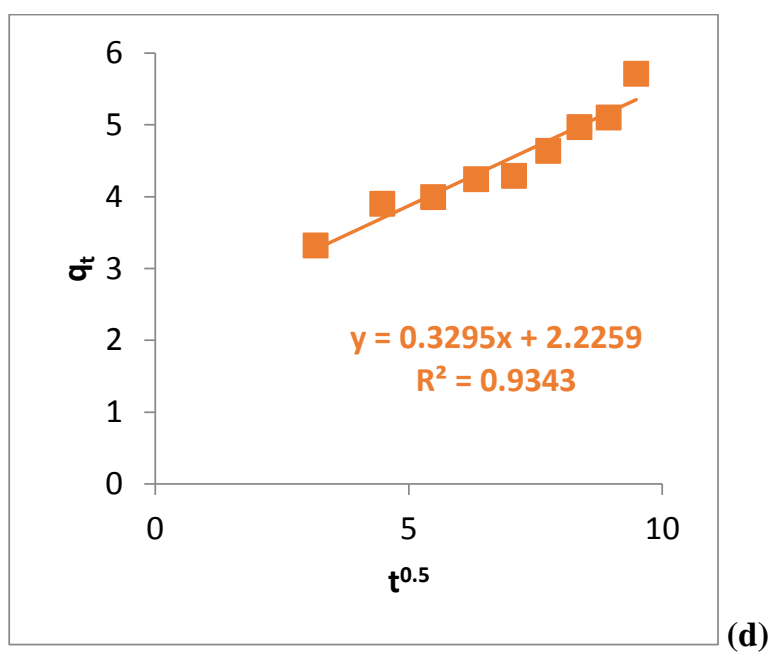

Fig. 8: Adsorption kinetic models (a) pseudo-first-order, (b) pseudo-second-order (c) Elovich and (d) Weber and Morris intra-particle diffusion for Cd(II) biosorption by GhMGDA (pH: 6.0, Adsorbent dose: $0.5 \mathrm{gm} / 50 \mathrm{ml}$, Initial $\mathrm{Cd}(\mathrm{II})$ concentration: $100 \mathrm{mg} / \mathrm{L}$, Temperature: $30{ }^{\circ} \mathrm{C}$, Agitation rate: $120 \mathrm{rpm}$ )

Table 2: Adsorption kinetics data for Cd(II) biosorption by GhMGDA

\begin{tabular}{|l|l|l|l|l|l|l|l|l|l|l|l|l|}
\hline \multicolumn{2}{|l|}{ Pseudo-first-order model } & \multicolumn{4}{l|}{ Pseudo-second-order model } & \multicolumn{3}{|l|}{ Elovich model } & \multicolumn{3}{l|}{ Intra-particle diffusion model } \\
\hline$q_{e}$ & $\boldsymbol{k}_{\boldsymbol{l}}$ & $\boldsymbol{R}^{\mathbf{2}}$ & $\boldsymbol{q}_{\boldsymbol{e}}$ & $\boldsymbol{k}_{\mathbf{2}}$ & $\boldsymbol{R}^{\mathbf{2}}$ & $\boldsymbol{\alpha}$ & $\boldsymbol{\beta}$ & $\boldsymbol{R}^{\mathbf{2}}$ & $\boldsymbol{K}_{\boldsymbol{i}}$ & $\boldsymbol{C}$ & $\boldsymbol{R}^{\mathbf{2}}$ \\
\hline 37.74 & 0.1974 & 0.8312 & 13.57 & 0.0018 & 0.9809 & 0.6972 & 0.3219 & 0.9742 & 0.3295 & 2.2259 & 0.9343 \\
\hline
\end{tabular}

\subsection{Thermodynamic studies}

Thermodynamic parameters are imperative factors that determine the feasibility and spontaneity of an adsorption process. The equilibrium constant at various temperatures and thermodynamic parameters of adsorption can be estimated from the following equations;

$\mathrm{K}_{\mathrm{c}}=\frac{\mathrm{C}_{\mathrm{Ae}}}{\mathrm{C}_{\mathrm{e}}}$

(C) IARJSET 


\section{International Advanced Research Journal in Science, Engineering and Technology}

Vol. 8, Issue 9, September 2021

DOI: 10.17148/IARJSET.2021.8909

$\Delta \mathrm{G}^{0}=-\mathrm{RT} \ln \mathrm{K}_{\mathrm{c}}$

$\Delta \mathrm{G}^{0}=\Delta \mathrm{H}^{0}-\mathrm{T} \Delta \mathrm{S}^{0}$

$\ln \mathrm{K}_{\mathrm{c}}=\frac{\Delta \mathrm{S}^{0}}{\mathrm{R}}-\frac{\Delta \mathrm{H}^{0}}{\mathrm{RT}}$

Where $K_{c}$ is the equilibrium constant, $C_{e}$ is the equilibrium concentration in solution $(\mathrm{mg} / \mathrm{L})$ and $C_{A e}$ is the amount of $\mathrm{Cd}(\mathrm{II})$ biosorbed on the biosorbent per liter of solution at equilibrium $(\mathrm{mg} / \mathrm{L}) . \Delta G^{\circ}, \Delta H^{\circ}$ and $\Delta S^{\circ}$ are changes in standard Gibbs free energy $(\mathrm{kJ} / \mathrm{mol})$, standard enthalpy $(\mathrm{kJ} / \mathrm{mol})$ and standard entropy $(\mathrm{J} / \mathrm{mol} \mathrm{K})$ respectively. $R$ is the gas constant $(8.314 \mathrm{~J} / \mathrm{mol} \mathrm{K})$ and $\mathrm{T}$ is the temperature $(\mathrm{K})[24]$.

The values of $\Delta H^{\circ}$ and $\Delta S^{\circ}$ were determined from the slope and the intercept from the plot of $\ln K c$ versus $1 / T$ (Fig. 9). The values of equilibrium constant $(K c)$, Gibbs free energy $\left(\Delta G^{\circ}\right)$, the standard change in entropy $\left(\Delta S^{\circ}\right)$ and the standard change in enthalpy $\left(\Delta H^{\circ}\right)$ were represented in Table 3. It was revealed that the value of standard Gibbs free energy change $\left(\Delta G^{\circ}\right)$ is small and negative and indicates the spontaneous nature of the biosorption. The values of $\Delta G^{\circ}$ were found to decreases as the temperature increases, indicating more driving force and hence resulting in higher biosorption capacity. The value of $\Delta H^{\circ}$ was positive, indicating the endothermic nature of the biosorption of Cd(II) onto GhMGDA. The positive value of $\Delta S^{\circ}$ shows an affinity of biosorbent and the increasing randomness at the solid-solution interface during the biosorption process [25].

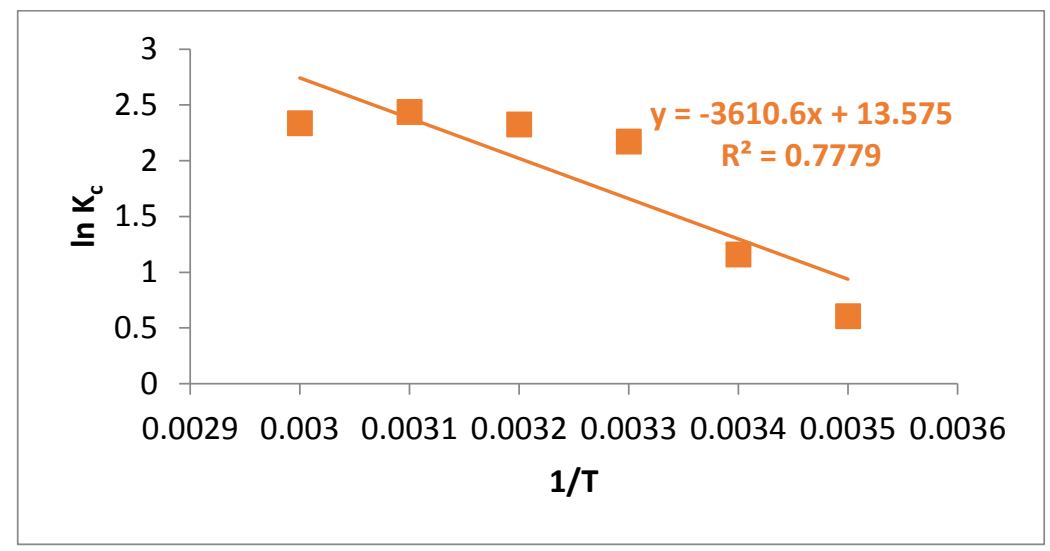

Fig. 9: Plot of $\ln K c$ against $1 / T$ for determination of thermodynamic parameters for Cd(II) biosorption by GhMGDA (pH: 6.0, Adsorbent dose: $0.5 \mathrm{~g} / 50 \mathrm{~mL}$, Cd(II) concentration: $100 \mathrm{mg} / \mathrm{L}$, Contact time: 90 minutes, Agitation rate: $120 \mathrm{rpm})$

Table 3: Thermodynamic parameters of Cd(II) biosorption by GhMGDA

\begin{tabular}{|c|c|c|c|c|c|c|}
\hline $\begin{array}{l}\text { Sr. } \\
\text { No. }\end{array}$ & $\begin{array}{l}\text { Temperature } \\
\left({ }^{0} \mathrm{C}\right)\end{array}$ & $\begin{array}{l}\text { Temperature } \\
(\mathrm{K})\end{array}$ & $K c$ & $\begin{array}{l}-\Delta G^{0} \\
(\mathrm{KJ} / \mathrm{mol})\end{array}$ & $\begin{array}{l}\Delta H^{0} \\
(\mathrm{KJ} / \mathrm{mol})\end{array}$ & $\begin{array}{l}\Delta S^{0} \\
(\mathrm{~J} / \mathrm{mol})\end{array}$ \\
\hline 1 & $10^{\circ} \mathrm{C}$ & 283 & 1.8353 & 1.4286 & \multirow[t]{6}{*}{30.0185} & \multirow[t]{6}{*}{112.86} \\
\hline 2 & $20^{\circ} \mathrm{C}$ & 293 & 3.1906 & 2.8263 & & \\
\hline 3 & $30^{\circ} \mathrm{C}$ & 303 & 8.7876 & 5.4750 & & \\
\hline 4 & $40^{\circ} \mathrm{C}$ & 313 & 10.2196 & 6.0485 & & \\
\hline 5 & $50^{\circ} \mathrm{C}$ & 323 & 11.4471 & 6.5464 & & \\
\hline 6 & $60^{\circ} \mathrm{C}$ & 333 & 10.3598 & 6.4727 & & \\
\hline
\end{tabular}




\title{
International Advanced Research Journal in Science, Engineering and Technology
}

\author{
Vol. 8, Issue 9, September 2021
}

\section{DOI: 10.17148/IARJSET.2021.8909}

\section{CONCLUSION}

Environmental pollution particularly from heavy metals and minerals in the waste water has turned out as a very serious problem in the Indian subcontinent. Biosorption is one amongst such evolving technologies, which utilizes naturally occurring biological materials to sequester heavy metals from wastewater. Methylglycinediacetic acid modified pericarp of Gossypium herbaceum L. (GhMGDA) as low-cost green adsorbent investigated in this study showed good potential for the removal of cadmium from aqueous solutions. The removal efficiency of GhMGDA was found to be dependent on the $\mathrm{pH}$, adsorbent dose, initial $\mathrm{Cd}(\mathrm{II})$ ions concentration, temperature, contact time and agitation rate. The adsorption isotherm study revealed that the adsorption equilibrium data best fitted to the Langmuir $\left(\mathrm{R}^{2}=0.9996\right)$ model in comparison to other isotherm models at the studied temperature. The maximum monolayer coverage adsorption capacity from the Langmuir isotherm model was obtained as $44.25 \mathrm{mg} / \mathrm{g}$. The sorption process was best described by a pseudosecond-order kinetic model. Thermodynamic study confirmed that the biosorption process was endothermic, spontaneous and proceeded with increased randomness. The study results signify that Methylglycinediacetic acid modified pericarp of Gossypium herbaceum L. can be efficiently used as a green adsorbent for the removal of Cd (II). Hence, the approach is sustainable in nature, owing to the fact that the green adsorbents as well as the chelating agents i.e. Methylglycinediacetic acid used for the modification of green adsorbents are biodegradable.

\section{REFERENCES}

1. Liu Y., Wang X., Yang F. and Yang X. "Excellent antimicrobial properties of mesoporous anatase $\mathrm{TiO}_{2}$ and $\mathrm{Ag}_{\mathrm{g}} \mathrm{TiO} \mathrm{O}_{2}$ composite films." Micropor. Mesopor. Mater, 114 (1), pp. 431-439, 2008.

2. Pamukoglu M.Y. and Kargi F. "Batch kinetics and isotherms for biosorption of copper (II) ions onto pre-treated powdered waste sludge (PWS).” Journal of Hazardous Materials, 138(3), pp. 479-484, 2006.

3. Nouri J., Alloway B.J. and Peterson P.J. "Forms of heavy metals in sewage sludge and soil amended with Sludge.” Pakistan J Biol. Sci., 4 (12), pp. 1460-1465, 2001.

4. Zhu B, Fan T.X. and Zhang D. “Adsorption of copper ions from aqueous solution by citric acid modified soybean straw.” J Hazard Mater, 153(1-2), pp. 300-308, 2008

5. Stephen B. and Sulochana N. "Carbonised jackfruit peel as an adsorbent for the removal of Cd (II) from aqueous solution." Bioresource Technology, 94, pp. 49- 52, 2004

6. Naiya T. K., Das S. K. and Bhattacharya A. K. “Adsorption of Cd (II) \& Pb (II) from aqueous solution on activated alumina.” J. Coll. Inter. Sci., 21, pp. 434-451, 2009.

7. Sankar R., Karthik A., Prabu A., Karthik S., Subramanian K. and Ravikumar V. "Origanum vulgare mediated biosynthesis of silver nanoparticles for its antibacterial and anticancer activity." Colloids Surf., B, 108, pp. 80-84, 2013.

8. $\quad$ Sanusi K.A., Sunday N.S., Hassan M.S. and Abdulqadir T.A. "The effect of operational parameters on biosorption of $\mathrm{Cd}^{2+}$, $\mathrm{Ni}^{2+}$ and $\mathrm{Cr}^{6+}$ using Glycine max pod (Soya Bean).” Environ Risk Assess Remediat, 2, pp. 26-34, 2018.

9. $\quad$ Singh K. K., Rupainwar D. C. and Hasan S. H. "Low cost biosorbent 'Maize Bran' for the removal of cadmium[II] from wastewater." J. Ind. Chem. Soc., 82, pp. 392-396, 2005.

10. Langmuir I. "The adsorption of gases on plane surface of glass, mica and platinum.” J. Am. Chem. Soc., 40, pp.1361-1403, 1918.

11. Freundlich H.M.F. "Uber dies adsorption in losungen, Zeitschriftfue Physikalische.” Chemie (Leipzig), A57, pp. 385-470, 1906.

12. Dubinin M.M. and Radushkevich L.V. "Equation of the characteristic curve of activated charcoal." Proc. Academy of Sci. Phy. Chem. Section, U.S.S.R., 55, pp. 331-333, 1947.

13. Olivieri N.F. and Brittenham G.M. "Iron-chelating therapy and the treatment of thalassemia." Blood, 89, pp. 739-761, 1997.

14. Temkin M.J. and Pyzhev V. "Kinetics of ammonia synthesis on promoted iron catalysts." Acta Physiochim. Urrs, 12, pp. 217-222, 1940.

15. Shroff K.A. and Vaidya V.K. "Kinetics and equilibrium studies on biosorption of nickel from aqueous solution by dead fungal biomass of Mucor hiemalis." Chem Eng J, 171, pp. 1234-1245, 2011.

16. Lagergren S. "About the theory of so-called adsorption of soluble substances." Handlinge, 24, pp. 147-156, 1898.

17. McKay G., Ho Y.S. and Ng J.C.Y. "Biosorption of copper from wastewaters: A review." Sep. Purif. Methi., 28, pp. 87-125, 1999.

18. Chien S.H. and Layton W.R. "Application of Elovich equation to the kinetics of phosphate release and sorption in soils." Soil Sci. Soc. Am. J., 44, pp. 265-268, 1980

19. Weber W.J. and Morris J.C. "Kinetics of adsorption on carbon solution.” J. Sanit. Eng. Div. Am. Soc. Civ. Engg., 89, pp. 31-59, 1963.

20. Septhum C., Rattanaphani S., Bremner J.B. and Rattanaphani V. "An adsorption of Al (III) ions onto chitosan.” J. Hazardous Materials, 148, pp. 185- 191, 2007.

21. Jadav J.N., Maind S.D. and Bhalerao S.A. "Biosorption of Lead (II) and Chromium (VI) onto Tarminalia Catappa L. Leaves: A Comparative Evaluation.” Journal of Applicable Chemistry, 4, pp. 1700-1715, 2015.

22. Thomas J.M. and Thomas W.J. "Principle and Practice of heterogeneous catalysis.” Weinheim, VCH, 1997.

23. Poojari A. C. and Bhalerao S. A. "Removal of lead (II) from aqueous solution by immobilized Sugarcane bagasse (Saccharum officinarum L.) onto calcium alginate beads." International Journal for Scientific Research \& Development, 4(12), pp. 470-481, 2018.

24. Catena G.C. and Bright F.V. "Thermodynamic study on the effect of cyclodixtrin inclusion with aniline naphthalene sulphonates." Anal. Chem., 61, pp. 905-909, 1989.

25. Sharma A. S. and Bhalerao S. A. "Sequestration of trivalent arsenic from aqueous solution by using banana peels (Musa paradisiaca L.) modified in calcium alginate beads.” International Journal for Research in Applied Science \& Engineering Technology, 6(3), pp. 3170-3184, 2018.

26. HIMANSHU SEKHAR BEHERA; Bijoy kumar pany. "Soil properties of medium land rice (Oryza sativa L.) in inorganic nitrogenous fertilizers on fym combination in yield". International Research Journal on Advanced Science Hub, 3, Special Issue ICIES-2021 4S, 2021, 46-49. doi: 10.47392/irjash.2021.109 